\title{
The role of pretest and test similarity in producing helpless or reactant responding in humans
}

\author{
ASHTON D. TRICE and PAUL J. WOODS \\ Hollins College, Roanoke, Virginia 24020
}

\begin{abstract}
In three experiments, the similarity between the pretest unsolvable training task and the subsequent test task for helplessness was examined. When pretest and test were dissimilar in both content (arithmetic vs. anagram problems) and mode of presentation, performance was enhanced on the test, compared with solvable and control groups (Experiments 1 and 2). The use of some solvable problems in the pretest was found to reduce the variability of results. When pretest and test were composed of similar problems, the typical helplessness pattern was exhibited (Experiment 3). External locus of control subjects were found to respond less under all experimental conditions (Experiment 1). The relationship between these data and the helplessness and reactance models of the effects of noncontingent failure is discussed.
\end{abstract}

Experience with uncontrollable aversive stimulation often produces characteristic response-initiation deficits in later escape/avoidance training. Such deficits have been labeled learned helplessness (Maier \& Seligman, 1976). Several experimental manipulations, however, have been detailed under which prior uncontrollable punishment or failure to solve problems actually potentiates either subsequent escape/avoidance learning or additional problem solutions. Such enhanced performance has been termed reactance: a condition of increased effort to assert control after an experience with uncontrollability (Wortman \& Brehm, 1975).

Wortman and Brehm (1975) identified two experimental parameters that may be manipulated to produce either helpless or reactant behavior: (1) amount of experience with uncontrollable outcomes and (2) importance of the pretest task. During the initial phases of experience with uncontrollable outcomes or unsolvable tasks, reactance is high. Over trials, however, as the subjects learn that there is nothing they can do to escape punishment or find solutions to the problems, helplessness replaces reactance. Also, subjects tend to show stronger levels of reactance when the uncontrollable events are of high importance than when they are of lesser importance, and the shift from reactant responding to helplessness is predicted to occur with fewer trials in more important tasks.

Roth and Kubal (1975) tested these hypotheses by varying both the number of trials and the importance of the pretest. Either a single 50-trial concept-formation problem or three problems with a total of 120 trials

Requests for reprints should be sent to Paul J. Woods, Department of Psychology, Hollins College, Roanoke, Virginia 24020. This paper is based on a thesis submitted by the senior author in partial fulfillment of the requirements for the Master's degree at Hollins College. were administered, for which there were no solutions. Importance was varied by informing subjects either that the problems were ordinary puzzles or that the problems were designed to replace the Scholastic Aptitude Test. The results supported the Wortman and Brehm (1975) model.

Thus, the variables of experience with uncontrollable outcomes and importance of pretest task influence learned helplessness, and evidence exists that other variables do so also. A substantial literature exists that shows that individual differences can intensify or obliterate the effects. Seligman (1975) reports that, when mongrel dogs were used, over one-third showed no signs of helplessness, while some dogs behaved helplessly with no laboratory experience with uncontrollability. The use of lab-reared animals, with histories controlled, eliminated such variability. Hiroto (1974) and Jones, Nation, and Massad (1977) report that subjects having high external scores on locus of control scales were more susceptible to helplessness manipulations than were internal subjects. Rotter (1966) proposed that an external score indicates that subjects perceive no contingency between their behavior and environmental outcomes. Such an attitude is seen as having been acquired by experience with uncontrollability. Klein, Fencil-Morse, and Seligman (1976) also found that depressed subjects were more prone to helplessness than were nondepressed subjects.

A study by Thornton and Jacobs (1972) found that experience with uncontrollable shock increased performance on a brief intelligence test by $38 \%$, while no shock or controllable shock had negligible effects, when compared with a previous administration of an alternate form of the test. This experiment suggested to us that, when pretest and test were tasks that were quite different, not only should there be no helplessness, but the 
previous experience should produce an increased effort to reassert control (reactance).

\section{EXPERIMENT 1}

The Thornton and Jacobs (1972) study suggests that test performance can be enhanced on a task dissimilar from the task used in the helplessness training. In this experiment, a mathematical pretest was used (numerical sequence problems), followed by a verbal test (anagrams). The pretest was a set of problems presented on individual forms, to be worked in any order at the subject's own pace. The anagrams were presented to the entire group, and each problem was separately timed. Locus of control was also examined.

\section{Method}

Subjects. Fifty-seven women enrolled in an introductory psychology course at Hollins College were enlisted as subjects.

Procedure. During a regularly scheduled session of the course, students in attendance were randomly assigned to one of three pretest groups. Tasks during the pretest consisted of seven solvable arithmetic sequence problems, seven unsolvable arithmetic sequence problems, or a "neutral" coding task. Subjects were told that they were part of an experiment designed to test the manner in which people shifted from solving one kind of problem to solving another. Both the pretest and the test tasks were explained prior to the beginning of the experiment, while answer forms were being passed out. The first task was explained as a series of mathematical problems in which, by adding, subtracting, multiplying, or dividing the previous number by a constant or by squaring the previous number, a numerical sequence would be generated. Each sequence was generated by using two or three of the operations in a recurring pattern. A simple example was worked by the experimenter. Subjects in the coding condition were informed by direction on the form that they were to rearrange 15 sequences of numbers into ascending numerical order. The test task for all groups was a series of 12 five-letter anagrams found to be relatively easy from previous pilot work. Presentation of the anagrams was by slides, each exposed for $30 \mathrm{sec}$. Subjects were instructed to record an X on the answer sheet if they had not solved the anagram in the $30 \mathrm{sec}$ during which it was exposed. There was no common pattern of letter rearrangement that would solve all anagrams.

Subjects were given $4 \mathrm{~min}$ to work on the pretest task. A 30-sec rest period was interposed between the pretest and the anagram testing. Subjects were debriefed at the end, as forms were being collected. I. E. scale scores (Rotter, 1966) had been collected previously by the course instructor.

\section{Results and Discussion}

Analysis by Duncan's new multiple range test showed that the unsolvable pretest group solved significantly more anagrams (mean $=8.5$ ) than did the coding controls (mean $=6.8$ ). The solvable pretest group was not significantly different from either controls or the unsolvable pretest group (mean $=7.4$ ).

Subjects were divided by the group median score of 11.5 on Rotter's (1966) I. E. scale into those with locus of control perceived as relatively internal and relatively external. Those with internal locus of control performed significantly better (mean $=8.2$ ) across experimental groups than did those with external locus of control (mean $=6.9)[\mathrm{t}(48)=1.93, \mathrm{p}<.05]$. Within the con- trol group, this difference was even more pronounced, with internal subjects solving an average of 8.3 anagrams and external subjects solving 5.1 anagrams $[\mathrm{t}(17)=2.32$, $\mathrm{p}<.01]$. Such results were in keeping with the studies by Hiroto (1974) and Jones et al. (1977), which suggested that external subjects would make fewer attempts at problem solutions than would internal subjects.

Within-group variability in this experiment was rather large. Informal contact with some subjects suggested a major source of such variability. Several students suggested that they "solved" the unsolvable problems by realizing that no solutions could be reached. Moreover, they reported carrying over this belief of experimenter hoax to the anagram test. Thus, if there were some solvable items in the "unsolvable" pretest condition, this source of variability might be eliminated.

\section{EXPERIMENT 2}

Experiment 2 involved a modified design in keeping with the above discussion. The "unsolvable" pretest contained some solvable problems. Also, since Dweck and Bush (1976) found sex differences in responding to helplessness procedures, we ran this study on a male population for comparison with the results of Experiment 1.

\section{Method}

Subjects. Twenty-four male volunteers from psychology courses at Washington and Lee University participated. Subjects were solicited to participate in an experiment designed to test the manner in which people shift from one problem solving strategy to another.

Procedure. Experiment 1 was modified by changing two of the unsolvable sequence problems to solvable sequences. Subjects were run in small groups outside of a classroom situation. I. E. data (Rotter, 1966) were not collected.

\section{Results and Discussion}

The largely unsolvable pretest group solved significantly more anagrams (mean $=7.6)$ than did either the solvable group $($ mean $=6.0) \quad[\mathrm{t}(14)=1.83, \mathrm{p}<.05]$ or the controls (mean $=6.2)[\mathrm{t}(14)=1.79, \mathrm{p}<.05]$. No significant differences in responding between the females in Experiment 1 and the males in this experiment were observed.

Importantly, no subjects questioned the solvability of the unsolvable sequence when informally questioned after debriefing. And none reported having suspected any experimental "hoax," as in the first experiment.

\section{EXPERIMENT 3}

The final experiment was conducted to determine whether a task that had previously elicited reactant responding could be used to produce helplessness by making the test more similar to the pretest.

\section{Method}

Subjects. Twenty-nine women students present at two consecutive meetings of an introductory statistics course at 
Hollins College were studied. One student was dropped because she had conducted a pilot study in this series of experiments.

Procedure. During a regularly scheduled class meeting, either the largely unsolvable, the solvable, or the coding tasks used in the previous experiment were administered. Two days later, 10 new solvable sequences of the same type were given, and subjects were allowed to work on them for $4 \mathrm{~min}$.

\section{Results and Discussion}

The number of correct solutions to the second set of sequence problems by the largely unsolvable pretest group was significantly smaller (mean $=4.0)$ than either controls (mean $=6.2)[\mathrm{t}(16)=3.13, \mathrm{p}<.01]$ or the solvable pretest group $($ mean $=6.5) \quad[\mathrm{t}(18)=2.81$, $p<.01]$. No significant difference existed between the controls and the solvable pretest group, which suggests that the data cannot be explained by practice effects.

\section{GENERAL DISCUSSION}

The most striking conclusion for the data reported above is that one can differentially produce "helpless" responding or enhance responding by varying the similarity of the test task to the unsolvable pretest task. Relatively few correct responses were made on a task that had been preceded by failure at that task. But, in contrast, enhanced performance occurred on the test task when it was dissimilar to the original task in both content and method of presentation.

While Wortman and Brehm (1975) suggest that relatively few helplessness trials on important tasks are necessary for the differential production of helplessness or reactance, these data suggest that these two factors are not sufficient in accounting for such results, as the same task was able to produce both phenomena.

Two differences exist between these methods and those typical of the helplessness literature. First, no consequent aversive stimuli were administered by the experimenter. All helplessness studies to date have used shock, noise, or experimenter feedback following each pretest trial to signal failure to solve the problem. In these studies, subjects were allowed to work on a set of problems for a specified period of time. The only possible negative feedback was failure to find a solution to a problem: In other words, the negative consequences were selfadministered. The technique of running subjects in groups, however, may have intensified the effects of failure, as subjects in the unsolvable pretest groups were able to observe successful completion of test items by subjects in the solvable and control groups. Ruble, Parsons, and Ross (1976) have observed that failure at a task at which a peer reference group has had success produces a greater lowering of expectations of future success than does failure at a task for which no reference group is available.

The second difference was the nature of the tasks themselves. Most helplessness studies have used either motor tasks or visual discrimination problems in at least one phase of the experiment. Problems in the above experiments were chosen to more closely resemble items encountered in academic and standardized test situations. Even when procedures such as anagram solutions have been used in the helplessness literature, the nature of the task has been quite different. The anagram task first described by Hiroto (1974), which is the most extensively used cognitive test task in the literature, uses a single rearrangement pattern, and subjects are cued that there is such a pattern. Thus, instead of a series of single problems, as described above, the Hiroto task is a single problem, and its solution may depend heavily upon the subject's trust or distrust of the experimenter's cue. When this task has been used, the typical results show only that the unsolvable pretest groups discover the pattern two or three trials later in the test than do solvable or control pretest groups.

Anagrams and numerical sequence problems are relatively novel problems for most subjects, and the training sessions used were relatively short. Longer training and the use of more familiar kinds of problems may have produced radically different results. If, for example, subjects encountered problems in the test with which they were quite familiar and with which they had experienced prior success in solution, helpless responding may be prevented by an uncontrolled "immunization."

\section{REFERENCES}

Dweck, C. S., \& Bush, E. S. Sex differences in learned helplessness: I. Differential debilitation with peer and adult evaluators. Developmental Psychology, 1976, 12, 147-156.

Нiroto, D. S. Locus of control and learned helplessness. Journal of Experimental Psychology, 1974, 102, 187-193.

Jones, S. L., Nation, J. R., \& Massad, P. Immunization against learned helplessness in man. Journal of Abnormal Psychology, $1977,86,75-83$.

Klein, D. C., Fencil-Morse, E., \& Seligman, M. E. P. Learned helplessness, depression, and the attribution of failure. Journal of Personality and Social Psychology, 1976, 33, 508-516.

Maier, S. F., \& Seligman, M. E. P. Learned helplessness: Theory and evidence. Journal of Experimental Psychology: General, 1976, 103, 3-46.

Roth, S., \& KUBAL, L. The effects of noncontingent reinforcement on tasks of differing importance: Facilitation and learned helplessness effects. Journal of Personality and Social Psychology, 1975, 32, 680-691.

RotTE R, J. B. Generalized expectancies for internal versus external control of reinforcement. Psychological Monographs, 1966, 80(1, Whole No. 609).

Ruble, D. N., Parsons, J. E., \& Ross, J. Self-evaluative responses of children in achievement settings. Child Development, 1976, 47, 990-997.

Seligman, M. E. P. Helplessness: On depression, development, and death. San Francisco: Freeman, 1975.

Thornton, J. W., \& JacoBs, P. D. The facilitating effects of prior inescapable/unavoidable stress on intellectual performance. Psychonomic Science, 1972, 26, 185-187.

Wortman, C. B., \& Brehm, J. W. Responses to uncontrollable outcomes: An integration of reactance theory and the learned helplessness model. In L. Berkowitz (Ed.), Advances in experimental social psychology (Vol. 8). New York: Academic Press, 1975.

(Received for publication October 22, 1979.) 